\title{
Information Technology Usage in SMEs in a Developing Economy
}

\author{
Ademola Afolayan \\ The University of South Wales, UK \\ Eoin Plant \\ The University of South Wales, UK \\ Gareth R.T. White \\ The University of South Wales, UK \\ Paul Jones \\ The University of Plymouth, UK \\ Paul Beynon-Davies \\ Cardiff Business School, UK
}

Information technologies are widely regarded as being capable of providing considerable strategic and operational value to organizations. Their implementation and development has been explored in a wide range of contexts. Studies have been made of large and smallscale organizations, in the public and private sectors, and in different regions of the world. Much of this research has identified the consider-able challenges associated with successful technology deployment. What has received comparatively minimal attention to date is the adoption of information technology businesses in developing economies. Arguably, these businesses are in greater need of such technologies in order to capitalize upon the benefits they may bring. However, organizations in these regions are faced with potentially unique difficulties and constraints.

This study reports the use of information technologies among small and medium-sized enterprises (SMEs) in a developing economy. A survey of 161 companies was undertaken in Lagos, Nigeria. It found that a variety of information technologies had been employed and that they had delivered considerable operational improvements. However, a lack of training and awareness is inhibiting their further use and development. Furthermore, a lack of infrastructure to supply consistent power and Internet services also inhibits their effectiveness. The issue of corruption was also identified as a considerable problem that affects user confidence. While this is a perennial problem that surrounds the use of information technologies in many countries, it appears markedly important in this economy. Consequently, it threatens to be a significant inhibitor to the uptake of technologies.

The role of SMEs in developing countries is an important one, contributing to economic growth and thereby job creation and poverty alleviation (Adekunle and Tella, 2008; Paul et al., 2008; Jones et al., 2014). SMEs are of particular significance to the economic development of Nigeria since they account for around $97 \%$ of privately owned businesses (Ihua, 2009). They have been recognized as the backbone of the economy, employing approximately $50 \%$ of the work force and providing more than $50 \%$ of Nigeria's industrial output (Adekunle and Tella, 2008). They play a significant role in enhancing the quality of human resources, generating employment, building a culture of entrepreneurship, supporting large- scale industries, and encouraging the creation of new business opportunities (Harindranath et al., 2008). 
SMEs serve many different roles within supply chains, as suppliers, distributors, producers, and customers (Hong and Jeong, 2006; Koh et al., 2007). The influence of globalization on SMEs has compelled many of them to adopt information communication technology (ICT) solutions in order to survive among increasingly competitive supply networks (Hsin and Anastasia, 2008; Ongori and Migiro, 2010; Stavrulaki and Davis, 2010; Olise et al., 2014). There has been a vast increase in the application and adoption of ICT in organizations for the storing, processing, distributing, and information exchange within the firm and along their supply chains (Apulu et al., 2011; Olise et al., 2014; Agboh, 2015). Firms utilize ICT for many purposes, including enhancing efficiency and cost reduction, and providing an enhanced service to their customers (Ashrafi and Murtaza, 2008; Apulu et al., 2011; Harrison and van Hoek, 2011).

This article is structured as follows: the first section introduces the importance of ICT in SMEs for the management of supply chain activities. Following that, the article explores the role of ICT in SMEs, along with the benefits and barriers of ICT adoption. Next, the research hypotheses are presented, along with the methodology adopted for the study. Finally, analysis and discussions are presented, before conclusions and recommendations for future research are stated.

\section{The role of ICT in SME supply chains}

Supply chain management (SCM) comprises a set of approaches and practices to efficiently incorporate manufacturers, distributors, customers, and suppliers, to improve the long-term performance of the individual firms and the supply chain as a whole (Koh et al., 2007). The main objective of effective SCM is to generate a source of competitive advantage for organizations to distinguish themselves from competitors by operating at a lower cost, thus at greater profit, and this can be aided by the adoption of ICT (Christopher, 2011).

Today's ICT solutions are broadly seen to encompass a wide range of 'software, hardware, telecommunication and information management techniques and applications that are used to create, produce, analyse, process, package, distribute, receive, retrieve, store and interpret information' (Barba-Sanchez et al., 2007, p. 105). The emergence of ICT has helped organizations achieve greater coordination and collaboration among supply chain partners and automate the supply chain process (Hsin and Anastasia, 2008). With advances in, and increasing availability of, ICT, manufacturers, their suppliers, and their distributors can be linked together into a seamlessly integrated organization (Stavrulaki and Davis, 2010; Ajayi and Olayungbo, 2014). The ability of SMEs to offer products and assemble goods at low prices within the quality standards stipulated by larger enterprises has helped increase the overall competition of the supply chain (Thakkar et al., 2009).

The implementation of ICT solutions to support SCM by SMEs can be cost saving for an organization in several ways (Hsin and Anastasia, 2008). It can increase flexibility, reduce the occurrence of errors in paper-based activities, achieve faster response times, and lower the cost of labour (Alam and Noor, 2009). In spite of efforts being made by many organizations to use ICT solutions to support their supply chain strategy, challenges still exist that inhibit effective integration (Christopher, 2011). Much of the literature recognizes this is largely due to the fact that most of the suppliers are SMEs that have limited skills and resources. This therefore makes their integration with the rest of the supply chain problematic (Adekunle and Tella, 2008). 


\section{ICT adoption benefits and barriers}

The adoption of ICT offers many benefits across a range of intra- and inter-firm business processes and transactions (Apulu and Latham, 2009). ICT is expected to provide SMEs with competitive advantage along with improved integration among supply chain trading part-ners (Bhagwat and Sharma, 2007). By contrast, it is argued that other firms can easily replicate the adoption of a particular ICT solution and therefore it does not necessarily provide a lasting competitive advantage for the adopting firm (Fasanghari et al., 2008).

The benefits of ICT adoption in SMEs have been widely explored in the extant literature. They include cost reductions and improved marketing (Shiels et al., 2003; Akpan-Obong, 2007; Akhavan and Jafari, 2008; Li et al., 2008; Oluwatayo, 2010; Singh, 2011), more efficient and effective communications (Chibelushi and Costello, 2009; Apulu et al., 2011; Singh, 2011; Pickernell et al., 2013; Ajayi and Olayungbo, 2014), as well as superior procure-ment and methods of distribution (Collins et al., 2010; Har-rison and Van Hoek, 2011; Ajayi and Olayungbo, 2014).

According to Fawcett et al. (2008) and Ihua (2009), SMEs are not a uniform or standardized set of businesses. They are in fact a highly heterogeneous collection of enterprises and vary substantially by size, sector, age, structure, and location. These characteristics can directly influence the organization's adoption of ICT (Apulu et al., 2011). Nath and Standing (2010) highlight the influence of company size on the adoption of ICT and note that it is also directly related to the type of industry to which the organization belongs.

Larger organizations are usually in possession of tech-nical, human, and financial resources which can be used to aid and enhance the adoption of ICT solutions. It is often a different case with SMEs, particularly in the face of limited financial and human resources (Ashrafi and Murtaza, 2008; Jones et al., 2011; Mpofu and Watkins- Mathys, 2011; Ajayi and Olayungbo, 2014). However, it has been argued that SMEs are sometimes able to exploit ICT opportunities and adopt ICT more easily than larger organizations, simply because of the flexibility advantage they possess that makes their decision-making faster (Chuang et al., 2009; Awa et al., 2011).

The barriers to utilization and adoption of ICT in SMEs can be broadly classified as internal and external (Jones et al., 2003; Kapurubandara and Lawson, 2006; Apulu et al., 2011; Awa et al., 2011). Internal barriers are those that exist within an organization and can also be resolved within the organization. They typically include organizational culture, lack of resources, owner/managers' attitude' toward ICT, and the level of training of employ-ees. The external barriers are those that lie outside the immediate control of the organization. These include a lack of infrastructural facilities and limited funds from banks and other governmental bodies. It has been suggested that in order for these inhibitors to be overcome, SMEs need to work collaboratively (Kapurubandara and Lawson, 2006).

Perhaps one of the most surprising barriers to ICT adoption is the lack of knowledge of ICT solutions, how they work, their implementation and perceived benefit to the SME sector (Adenikinju, 2005; Arendt, 2008; Asharfi and Murtaza, 2008). Prior studies have demonstrated that most owner/managers of these firms, and some of the employees, could not select an ICT solution that would be appropriate for a given type of organizational problem (Apulu and Latham, 2009; Abor and Quartey, 2010). Hence, there is a need for both the owner/managers and the employees to undergo appropriate training in order to be aware of the evolving nature of ICT and identify the optimum solution for their firm (Paul et al., 2008). However, many owner/managers fear that they will lose their employees to other firms after investing in training (Arendt, 2008; Jones et al., 2013).

The number of ICT graduates has fallen sharply in many countries, despite a general increase in the requirement for skilled recruits. Businesses have also criticized universities for not adequately preparing ICT graduates for the workplace, commenting that they are lacking in relevant experience, general business knowledge, and interpersonal skills 
(Doucek and Novotny, 2007; Koppi et al., 2008; Miliszewska, 2008; Oxford Economics, 2009; Llorens et al., 2013). If this trend continues, then one could expect ICT skills in SMEs and even larger companies to become severely depleted and ICT adoption to become even more challenging.

The adoption of ICT in SMEs may also require considerable effort from its users, who need to learn how to use the system and optimize its functionality to deliver greater value (Korpelainen and Kira, 2010). Furthermore, highly experienced employees of a firm might become entrenched with a particular software or system and then find it difficult to adopt new technology (Paul et al., 2008). However, a rapid rate of adoption can be seen when an organization identifies that an innovation or new technology is meeting the needs of the customer (Alam et al., 2007).

Nguyen (2008) argues that there are three main reasons for the slow rate of adoption and unsuccessful implementation of ICT in SMEs. Firstly, the management of the firms is not transparent about how and why their firms should adopt ICT initially (Chibelushi and Costello, 2009; Modimogale and Kroeze, 2011). Owner/ managers of SMEs do not understand the relationship between ICT and the firm: for example, younger owner/ managers tend to be fascinated by unique and fresh initiatives and are more willing to take risks than older owner/ managers. An older owner/manager may therefore be reluctant to take risks to try out a new technology (Chuang et al., 2009). Finally, the ever-changing ICT environment requires regular updates and training to remain abreast of developments and opportunities (MacGregor and Vrazalic, 2006; Modimogale and Kroeze, 2011).

The attitude of management in an organization plays a crucial role in the adoption of ICT as in most cases in SMEs the managers are also the owners (Apulu and Latham, 2009). Support from the management of an organization, most especially top management, is essential for successful ICT implementation and adoption for SMEs (Matlay and Addis, 2003). If the management is not disposed to its adoption and utilization, then SMEs will not be able to use ICT (Akpan-Obong, 2007; Agboh, 2015). The owner/manager's weakness therefore becomes a limitation of the business as well (Modimogale and Kroeze, 2011; Faloye, 2014).

Secondly, security and reliability issues also significantly inhibit ICT adoption and range, from the fear of computer viruses to the theft of money during electronic transactions and data theft (Arendt, 2008; Scupola, 2009). The presence of hackers gaining access to people's information and the level of fraud is one of the major barriers to ICT adoption in Nigeria (Olusegun et al., 2006). The majority of people do not believe that their information is safe online. For this reason, individuals and SMEs might be reluctant to perform transactions online that require the exchange of personal information (Olusegun et al., 2006; Faloye, 2014). The lack of trust in supply chains can be argued not to be the fault of the organization, since customers might not be interested in using the ICT solutions offered by a firm. This can be for reasons that include the potential for data or money theft (Olusegun et al., 2006). Such developments may also require a restructuring of the entire logistics and supply chain system to more effectively serve and retain customers (Arendt, 2008), and this may be the reason for a firm to shun the idea of implementing ICT solutions.

Thirdly, most SMEs do not have the capability to expand their ICT resources due to limited access to capital (Paul et al., 2008; Faloye, 2014; Agboh, 2015). This is a common factor that affects the adoption of ICT in SMEs (Arendt, 2008; Mpofu and Watkins-Mathys, 2011). The majority of SMEs in Nigeria do not have access to bank loans or funding to support the development of ICT in their businesses (Olorunshola, 2003; Olusegun et al., 2006). Moreover, paying back loans that have high interest rates/bank charges can be too much of a burden for the majority of typical SMEs (Abor and Quartey, 2010).

As mentioned previously, poor infrastructure can also be a problem that affects the adoption of ICT. Lack of Internet access is recognized as a barrier to the adoption of ICT in Nigerian SMEs. It cannot be claimed that Nigeria completely lacks the necessary 
infrastructure, but it can be argued that the infrastructure is substandard (Oshikoya and Hussain, 2007; Achimugu et al., 2009). The unstable nature of the electricity supply in Nigeria is one of the key factors affecting the adoption of ICT: information technologies work hand-in-hand with stable sources of electricity supply (Apulu and Latham, 2009). In fact, it can be argued to be the most discouraging factor of ICT adoption by SMEs in a country as a whole (Akpan- Obong, 2007).

Setting up the required infrastructure is expensive and requires significant funding (Achimugu et al., 2009; Arikpo et al., 2009). Some individuals have taken it upon themselves to acquire and set up the necessary infrastructure required to run the organization and to more effec-tively serve their customers (Ashrafi and Murtaza, 2008). For example, the Chairman of Globacom, Mike Adenuga, introduced a 9800-km-long cable network across the UK, Spain, Portugal, and 14 African countries in order to establish a dedicated link to the USA. This is the first initiative of its kind to be executed by an individual in Nigeria (Nkanga, 2011).

\section{Research framework}

The literature highlights the challenges that face SMEs when seeking to improve their performance through the use of ICT. From one perspective, the benefits of apposite technologies can be significant. However, the perceived and actual barriers to implementation are numerous, and not all of them lie within the sphere of control of the organization. SMEs in developing economies may also face specific problems when attempting to coordinate their activities with other inexperienced organizations within the supply chain, and when national infrastructures are not supportive of chosen technologies. The fol-lowing hypotheses have been drawn from the themes identified within the literature and form the basis of this investigation:

H1: The adoption of ICT by Nigerian SMEs will be positively related to the perceived ease of using ICT.

H2: There is a positive relationship between ICT adoption and perceived benefits in SMES.

H3: The adoption of ICT by Nigerian SMEs will be positively related to the size of the organization.

H4: The adoption of ICT by Nigerian SMEs will vary by industrial sector.

H5: The adoption of ICT by Nigerian SMEs will be dependent on the position of the organization in the supply chain.

H6: The perceived ease of use will have a positive relationship with the perceived usefulness of ICT to Nigerian SMEs.

\section{Methodology}

The survey research strategy is a widely accepted and common approach in business and management research (Saunders et al., 2007; Bryman and Bell, 2009; Panneerselvam, 2010). It is aimed at producing generalizations about a population by collecting information from samples. It is used for exploratory and descriptive research and usually associated with the deductive approach (Thomas, 2006; Saunders et al., 2009). Surveys are used as they allow for the collection of a large amount of data from a large population in a highly economical way (Bryman and Bell, 2011).

This study employed a self-administered questionnaire technique with the help of three field personnel for both distributions and collections. The questionnaire was addressed to the 
owner/manager of the companies surveyed, seeking their permission to take part in the study.

Details of active and registered SME businesses with the Lagos Chamber of Commerce and Industry ( $\mathrm{LCCl}$ ) were obtained and companies were chosen at random in order to obtain a representative sample. The questionnaire was developed drawing precedent from the previous studies of Onugu (2005) and Bhaskaran (2008). Although their study was based on SMEs, the questionnaire used for this study was refined to explore the importance of SCM in SMEs in accordance with the themes identified in the literature review (Ashrafi and Murtaza, 2008; Apulu et al., 2011).

The survey questionnaire was divided into three sections: Section 1 focused on collecting demographic information about the company; Section 2 explored the use of ICT in the supply chain; and Section 3 focused on the benefits and barriers of ICT adoption. Questions were answered through a five-point Likert scale. Some questions included openended responses to elicit further detail and accommodate a wider range of responses. A pilot test was carried out on the questionnaire to refine and restructure it (Saunders et al., 2007).

A total of 300 questionnaires were distributed to owner/managers of SMEs in Lagos, Nigeria. A covering letter was attached to the questionnaire stating the purpose of the study and assuring the anonymity of the respondents and their organization. Overall, 180 questionnaires were returned, of which 161 were complete, representing a response rate of $54 \%$. This sample size is considered adequate for analysis and the response rate is similar to that of Apulu et al. (2011).

\section{Analysis and discussion}

Ajayi and Olayungbo (2014), Olise et al. (2014), and Agboh (2015) note that there is no clear definition of SMEs in Nigeria, neither is there a generally acceptable definition. However, the number of employees is usually used to characterize SMEs (Modimogale and Kroeze, 2011). For example, the Small and Medium Sized Development Agency of Nigeria (SMEDAN) defines a micro enterprise as a business employing less than 10 people and with an annual turnover of less than five million naira, a small enterprise as a business with between 10 and 49 employees and an annual turnover of 5-49 million naira, and a medium enterprise as a business with between 50 and 199 people and an annual turnover of 50499 million naira. Meanwhile, the National Economic Reconstruction Fund (NERUND) describes a small enterprise as having an annual turnover of 10 million naira, and the Central Bank of Nigeria (CBN) defines a small-scale enter-prise for the Small and Medium Enterprise Equity Investment Scheme (SMEEIS) as having an annual turnover of 1.5 billion naira, excluding land and working capital (Olise et al., 2014). Adopting the SMEDAN definitions, analysis of the survey data demonstrated that 63 organizations (39.1\%) are micro enterprises employing less than 10 people, 72 organizations (44.7\%) are small enterprises, and 26 organizations (26\%) are medium-sized enterprises.

Figure 1 demonstrates that 50 respondents (31.1\%) had been in existence for less than 5 years, 51 respondents (31.7\%) sit within the range of 5-10 years, 23 respondents (14.3\%) within the range of 11-15 years, 16 respondents (9.9\%) within the range of 16-20 years, and 21 respondents (13\%) had been in existence for more than 20 years. This analysis suggests that SME organizations are a vibrant section of commerce in Nigeria. Small and micro-sized enterprises form the majority of the sample surveyed. Encouragingly, around one-third of those organizations have prospered for more than 10 years. 


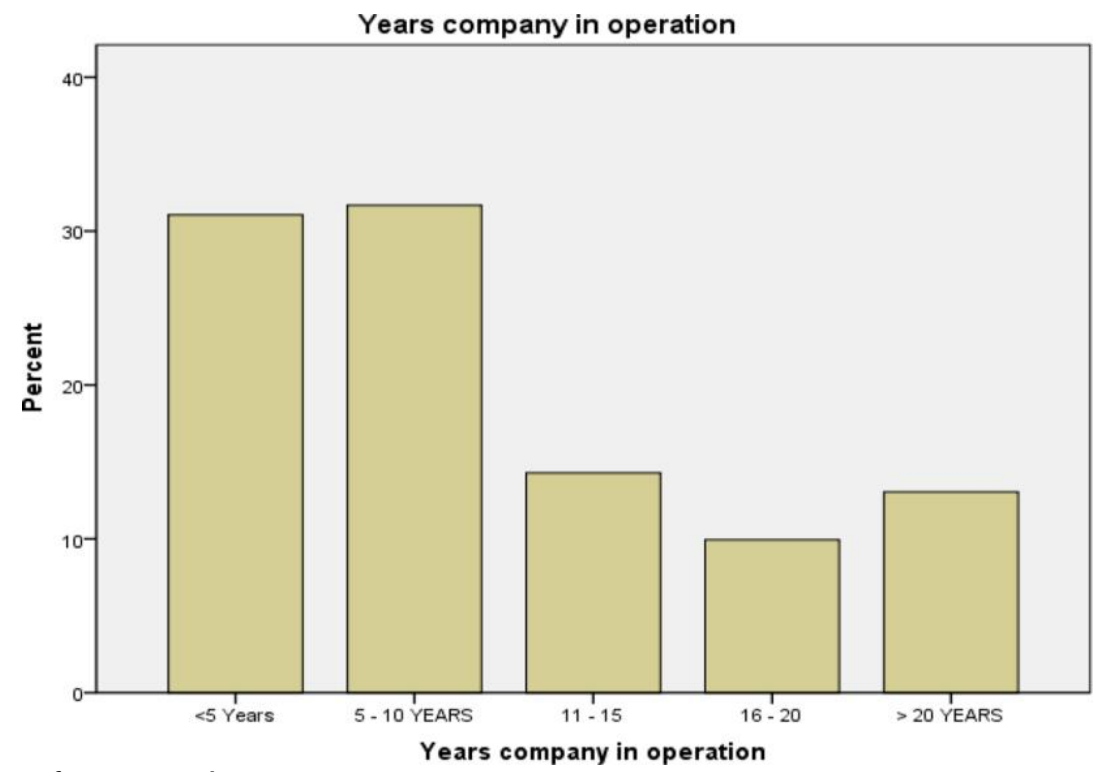

Figure 1. Age of companies.

In total, 31 organizations (19.3\%) were private limited companies, 16 organizations (9.9\%) were public limited companies, 27 organizations (16.8\%) were partnerships, 60 organizations (37.3\%) were sole proprietorships, and $26(16.1 \%)$ were family-owned businesses. A total of 113 organizations $(70.2 \%)$ identify themselves as belonging to tier 0 - that is, supplying directly to the consumer, 35 organizations (21.7\%) were reported as tier 1 , and 13 organizations (8.1\%) were reported as tier 2. Figure 2 depicts the range of sectors that the survey sample operated in.

Despite making an overall acceptance of Hypothesis 1 (Table 1), an independent sample ttest (Table 2) demonstrated that there were no relationships between ICT adoption and perceived ease of use of the following ICT tools: SMS, mobile phone, and fax. The analysis found that the difference in mean between adopters and non- adopters did not reach statistical significance for SMS, mobile phone, and fax.

Pearson's $r$ and Cohen's $d$ effect sizes were calculated to assess the differences between the means. Barcode scanner showed minimal significance, video conferencing showed medium-to-low effect size between the two groups. The SME owner/managers that took part in the survey were asked for the reasons why they had not adopted ICT solutions: $8.6 \%$ of respondents suggested that it was not applicable to their line of business, $7.4 \%$ respondents said it was not economical, $4.9 \%$ respondents said they were not trained to use ICT solutions, $2.4 \%$ respondents said they were not aware of their usefulness, and $1.8 \%$ noted their ignorance of the ICT tools avail-able. The above analysis suggests that Nigerian SMEs are not fully aware of the benefits ICT may bring to specific business functions and processes, or they fail to consider the ways in which ICT may be able to improve an organization's efficiency and effectiveness.

Hypothesis 2 shows an overall acceptance, as represented in Table 1. However, the result of the independent sample $t$-test for the ICT subcategories represented in Table 2 shows that there is no significant difference between the adoption of ICT tools and current trends/ technology, automation of records, improved marketing, efficiency/speed, communication, and information storage. While competitive advantage showed a medium significant difference with Cohen's $d$ value of 0.635 and Pearson's $r$ value of 0.30 , global reach and reduced cost/ efficiency showed low and medium-to-low, respectively, with Cohen's $d$ value of 0.397 and 0.496 , respectively, and Pearson's $r$ value of 0.195 and 0.240 , respectively. 
This is in contrast with the main body of literature that examines ICT adoption in many contexts.

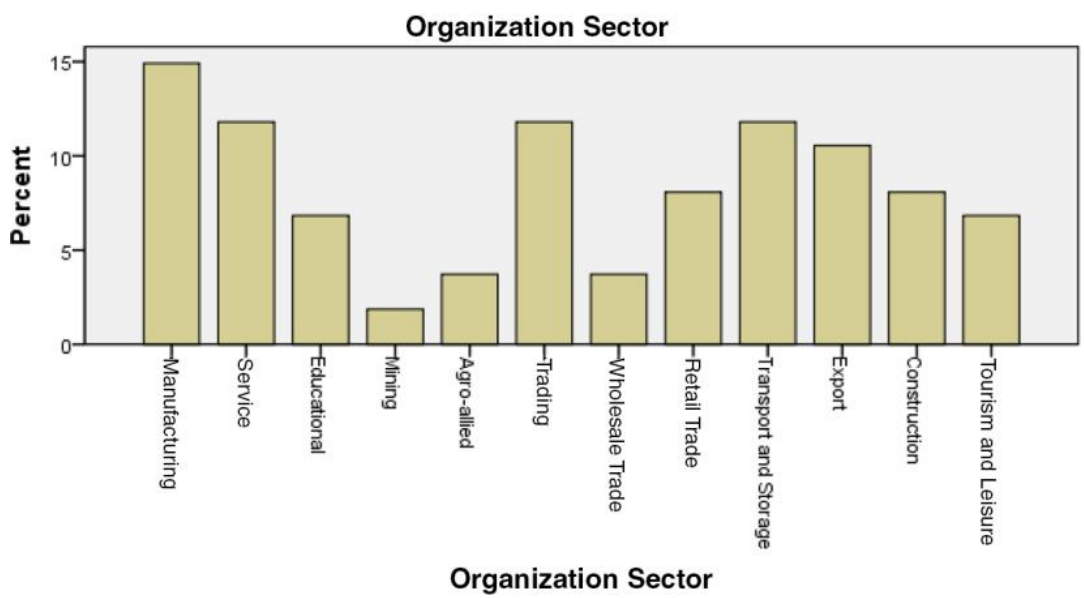

Figure 2. Sectors of commerce.

Table 1. Summary of hypotheses

\begin{tabular}{|c|c|c|c|}
\hline Hypothesis & Variables & Test & Result \\
\hline Hypothesis 1 & $\begin{array}{l}\text { The adoption of ICT by Nigeria SMEs will } \\
\text { be positively related to the perceived ease } \\
\text { of using ICT. }\end{array}$ & $t$-test & Accepted \\
\hline Hypothesis 2 & $\begin{array}{l}\text { There is a positive relationship between ICT } \\
\text { adoption and perceived benefits in SMES. }\end{array}$ & $t$-test & Accepted \\
\hline Hypothesis 3 & $\begin{array}{l}\text { The adoption of ICT by Nigeria SMEs will } \\
\text { be positively related to the size of the } \\
\text { organization. }\end{array}$ & Pearson $x^{2}(p=0.002)$ & $\begin{array}{l}\text { Accepted Cramer's } \\
d=0.227 \text { vs. } \\
p=0.002\end{array}$ \\
\hline Hypothesis 4 & $\begin{array}{l}\text { The adoption of ICT by Nigeria SMEs will } \\
\text { vary by industrial sector. }\end{array}$ & Pearson $x^{2}(p=0.121)$ & Rejected \\
\hline Hypothesis 5 & $\begin{array}{l}\text { The adoption of ICT by Nigeria SMEs will } \\
\text { be dependent on the position of the } \\
\text { organization in the supply chain. }\end{array}$ & Pearson $x^{2}(p=0.335)$ & Rejected \\
\hline Hypothesis 6 & $\begin{array}{l}\text { The perceived ease of use will have a positive } \\
\text { effect on the perceived usefulness of ICT } \\
\text { to Nigeria SMEs. }\end{array}$ & Pearson correlation & Accepted \\
\hline
\end{tabular}

Overall, $65 \%$ of the respondents identified that the lack of electricity supply was one of the main factors limiting the utilization and adoption of ICT, and was a notable barrier to its usability. There are unstable and limited power allocation networks in Nigeria, hence power shedding is a regular occurrence (Olatokun, 2008). The lack of infrastructure and the high cost of equipment were also identified by many of the respondents as other factors affecting the adoption of ICT.

For this study, in the context of a developing economy, it is encouraging to find that attitudes toward ICT adoption in SMEs are similar. Although requiring further investigation, along with the analysis of Hypothesis 1, it suggests that Nigerian SMEs' understanding of ICT is well developed. It is worth mentioning that most SME owner/ managers had received ICT training privately (43.5\%), followed by owner/managers who had received training from friends (18\%) and from government (17.4\%). 
In accord with much of the literature, Hypothesis 3 finds a strong relationship between the size of the company and the adoption of ICT. From our sample, of the respondents that were micro-scale enterprises, $74 \%$ had adopted some form of ICT, while $94 \%$ of smallscale enterprises and $92 \%$ of medium-sized enterprises had adopted information technologies. Although there does not appear to be a linear relationship between size and adoption, the analysis does suggest that smaller firms find it particularly difficult to adopt ICT.

Table 2. Analysis of $t$-tests by ICT subcategories

\begin{tabular}{lllllll} 
Hypothesis ICT subcategory & $\boldsymbol{t}$-Value & Sig. $(\boldsymbol{p})$ & \multicolumn{2}{l}{ Effect Size } & Result \\
\cline { 5 - 6 } & & & & $(\boldsymbol{d})$ & $(\boldsymbol{r})$ & \\
1 & Computer & -3.385 & 0.003 & 1.5 & 0.603 & High \\
1 & Barcode scanner & -2.100 & 0.037 & 0.33 & 0.16 & Low \\
1 & File sharing & -4.286 & 0.000 & 0.66 & 0.32 & Medium \\
1 & Data storage & -3.541 & 0.001 & 0.55 & 0.27 & Medium \\
1 & SMS & -1.504 & 0.293 & & & Not significant \\
1 & Website & -6.041 & 0.000 & 0.095 & 0.43 & High \\
1 & Internet connection & -2.955 & 0.008 & 1.3 & 0.55 & High \\
1 & E-mail & -3.179 & 0.005 & 1.38 & 0.57 & High \\
1 & Video conferencing & -2.541 & 0.012 & 0.40 & 0.198 & Medium-low \\
1 & Mobile phone & -1.707 & 0.103 & & & Not significant \\
1 & Fax & -0.971 & 0.333 & & & Not significant \\
2 & Competitive advantage & -3.760 & 0.000 & 0.635 & 0.30 & Medium \\
2 & Global reach & -2.353 & 0.020 & 0.397 & 0.195 & Low \\
2 & Current trend/technology & -3.324 & 0.764 & & & Not significant \\
2 & Automation of records & -0.546 & 0.586 & & & Not significant \\
2 & Customer satisfaction & -4.885 & 0.000 & 0.828 & 0.382 & High \\
2 & Improved marketing & -1.496 & 0.137 & & & Not significant \\
2 & Increased profit & -20.413 & 0.000 & 3.460 & 0.86 & Very high \\
2 & Efficiency/speed & -1.063 & 0.289 & & & Not significant \\
2 & Communication & -0.642 & 0.522 & & & Not significant \\
2 & Information storage & -1.082 & 0.281 & & & Not significant \\
2 & Reduced costs/efficiency & -2.930 & 0.004 & 0.496 & 0.240 & Medium-low
\end{tabular}

There is a perspective that believes older organizations (over 20 years) may be more willing and able to adopt ICT solutions compared with newer organizations (5-10 years) as their financial positions become secure, their awareness of the market improves, and their employees' skills increase. However, the study demonstrated that new organizations (34\%) seem to have adopted ICT solutions to a greater degree than old ones (14.9\%). There may be several reasons for this, ranging from increased ICT awareness of younger managers to increasing competition between organizations as newer ones enter the market.

The sample that was surveyed encompassed a broad range of industry sectors (Figure 2), but no relation was found between this and the adoption of ICT for Hypothesis 4. The Manufacturing sector was found to have the highest figure for ICT adoption (17.0\%), followed by Transport and Storage (12.1\%) then Trading (11.3\%).

No statistical relationship was found between the adoption of ICT and an organization's position in the supply chain for Hypothesis 5. However, in the sample $97 \%$ of tier 0 companies had adopted some form of ICT compared with 31\% of tier 1 suppliers and 13\% of tier 2 suppliers. This is compelling evidence that there is in fact some association between the adoption of ICT and the position of a company in a supply chain that is worthy 
of further investigation. Responses to open-ended questions indicated that tier 0 firms adopted and utilized ICT extensively for communication with end users.

The strong relationship found for Hypothesis 6, similar to that for Hypothesis 2, confirms much of the existing literature. The perceived ease of use of ICT solutions will have a positive effect on the usefulness of ICT to Nigerian SMEs. The poor service provided by Internet service providers (ISPs) was seen as a major concern by many respondents. This is characterized by slow Internet speed due to low bandwidth and high subscription costs. Thus, ISPs need to enhance the quality of services they provide to customers, especially regarding bandwidth, as this will assist SMEs to effectively utilize and adopt ICT solutions.

\section{Corruption - an issue of special concern}

Many of the findings of this study concur with the perspectives of ICT adoption that are widely discussed in the literature. Some factors seem to be unique to Nigeria and are of value to improving our knowledge of ICT adoption in developing economies. The majority of these issues may be addressed by the organizations themselves. Other issues, such as the provision of affordable and reliable power supplies and telecommunications, require attention at a national level. Corruption was highlighted by $53 \%$ of the respondents as one of the factors limiting the successful utilization and adoption of ICT: many of these offered accounts of the difficulties it presents in response to the open-ended survey questions. In Africa it is a problem of routine deviation from established standards and norms by public officials and parties with whom they interact (Ayobami, 2011). Bribery, private gain, and non- existent workers, also known as 'ghost workers,' are some of the different types of corruption that are prevalent. Corruption is therefore a potentially significant inhibitor of ICT adoption: it may influence adoption and improvement initiatives at the level of the organization as well as at the national level. Furthermore, it is a social issue and is therefore a challenging problem to address. Endemic corruption in Nigeria is a social problem that has attracted the interest of several scholars (Smith, 2007). However, its effect on e-commerce usage has attracted minimal attention.

The national growth of e-commerce is held back by lack of public awareness about how to use the technologies. There has been a rapid growth in electronic cash- transfer services such as Western Union, MoneyGram, and Travelex in recent years. Electronic banking is one area of e-commerce that has proven successful in Nigeria. Virtually all banks in Nigeria offer online, real-time banking services. Banks that cannot offer these services are increasingly losing their customers. Even though the Nigerian government has taken progressive steps in recent years to aid online buying and selling, many challenges still remain. Among these, some forms of corruption appear to be widespread:

'Yahoo Yahoo' Syndrome. Many young Nigerians attribute this to a lack of employment and tangible jobs. Therefore, they involve themselves in what is known as 'yahoo yahoo.' This is a type of online fraud where typically young men attempt to acquire people's banking details in order to purchase goods online without the owner's consent. The perpetrators of this crime spend long hours in cyber cafés surfing the net, with the aid of specialized software, to hack people's accounts.

'Phishing.' Online job applications are often fraught with danger, as fraudulent websites redirect applicants to unsecure 'phishing' web pages (Chaffey and White, 2010). Applications for vacancies in the military, for example, require the purchase of a 'pin' number to access the service, and this has normally been under-taken through a bank. However, this is increasingly being offered directly through the website, opening up the opportunity for personal banking details to be acquired, often without fear of discovery and hardly any prosecutions. 


\section{Conclusion}

SMEs are known to be the backbone of the economy in developed and developing countries. Nigeria in particular has advanced immensely through the numerous benefits that ICT provides. Cost reduction, increased flexibility, error reduction, faster response time, and lower cost of labour are some of the benefits that are reported. In spite of this, challenges still exist that inhibit effective integration.

This study contributes to our understanding of an under-researched field. The successful adoption of ICT in developing economies is an essential component of their ability to make a significant contribution and is necessary for their continued growth. The general findings are concomitant with those of other studies in both developed and developing economies. However, the study was confined to businesses in Lagos, Nigeria and though the specific findings are indicative of the issues that may pervade other countries and regions, further study is required to confirm the generalizability of this study's conclusions.

In terms of implications for business practice, there is a need for both managers and employees to undergo continual training in order to be aware of the changing nature of ICTs and to find the most suitable solution for their organization. However, it is encouraging to note that the current level of understanding of ICT among Nigerian SMEs is reasonably well developed. The lack of security and reliability, trust, and access to capital are some of the factors responsible for the slow adoption of ICT within the SME sector in Nigeria.

ICT adoption in developing economies appears to present additional challenges to those that are experienced in the majority of system implementations and developments, and are discussed widely in the literature. Firstly, the national infrastructure may be inadequate to foster confidence and utilization of ICT by existing organizations, and perhaps even more importantly it may also be inadequate to encourage further development of ICT for the betterment of the economy. This may be a particular issue that impedes the adoption of ICT throughout supply chains and networks, and inhibits its uptake among micro-sized businesses. Secondly, corruption is a perennial problem in some areas and does not seem to be an easy issue to resolve. Nevertheless, ignoring the problem is unacceptable given its reported magnitude.

There would appear to be a need for both SMEs and government institutions to cooperate in addressing these pressing problems. Organizations ought to ensure the readiness of their employees for the change that is brought about through ICT solutions. This should not just be restricted to their employees, but should recognize the multiplicative effect of appropriate ICT adoption through-out the supply chain. Infrastructure development needs to take place to complement the development of SME- based commerce. The cost of these undertakings should be considered in light of the considerable importance of SMEs to the economy.

Despite these local and national challenges, this study finds that ICT adoption in Nigeria is encouragingly wide-spread among companies of different sizes and in different economies. Business managers appear well versed in ICT and look upon it as a source of competitive advantage and a means of achieving improvements in efficiency and effectiveness. Emerging and developing economies are often overlooked in research projects, but are a significant part of global economic development. They present unique challenges that require resolution before they result in inefficient or ineffective ICT policies and systems being introduced, with irrevocable design flaws or limitations. Future research should take account of the significant effect that larger-scale issues, such as corruption and infrastructure development, can have upon ICT adoption and effectiveness. Research could also explore the geospatial relationship between power and informatics infra-structures and the prevalence of ICT adoption. 


\section{References}

Abor J, Quartey P. 2010. Issues in SME development in Ghana and South Africa. International Research Journal of Finance and Economics 39: 218-228.

Achimugu P, Oluwagbemi O, Oluwaranti A, Afolabi B. 2009. Adoption of information and communication technologies in developing countries: An impact analysis. Journal of Information Technology Impact 9(1): 37-46.

Adekunle P, Tella A. 2008. Nigeria SMEs participation in electronic economy: Problems and the way forward. Journal of Internet Banking and Commerce 12(3). Available at: www. unilorin.edu.ng/publications/tellaa/http_ _www.arraydev. com_commerce_JIBC_200812_JIBCArticleTemplate-Tella\%5B1\%5D.pdf.

Adenikinju AF. 2005. Analysis of the cost of infrastructure failures in a developing economy: The case of the electricity sector in Nigeria. African Economic Research Consortium (AERC), Research Paper 148, February.

Agboh D. 2015. Drivers and challenges of ICT adoption by SMES in Accra metropolis, Ghana. Journal of Technology Research 6. Available at: www.www.aabri.com/manuscripts/ 142044.pdf.

Ajayi A, Olayungbo D. 2014. ICT adoption in small and medium scale enterprises in Nigeria: An assessment. International Journal of Research 1(9): 889-897.

Akhavan P, Jafari M. 2008. Towards learning in SMEs: An empirical study in Iran. Development and Learning in Organisations 22(1): 17-19.

Akpan-Obong P. 2007. Information and communication technology in development: Contextuality and promise. Proceedings of the 9th International Conference of Social Implication of Computers in Developing Countries, São Paulo, Brazil, pp. 1-14.

Alam SS, Noor MKM. 2009. ICT adoption in small and medium enterprises: An empirical evidence of service sectors in Malaysia. International Journal of Business and Management 4(2): 112-125.

Alam S, Khatibi A, Ahmad M, Ishmail H. 2007. Factors affecting e-commerce adoption in the electronic manufacturing companies in Malaysia. International Journal of Commerce and Management 17(1/2): 125-139.

Apulu I, Latham A. 2009. Information and communication technology adoption: Challenges for Nigerian SMEs. TCM Academic Journal 4(2): 64-80.

Apulu I, Latham A, Moreton R. 2011. Factors affecting the effective utilisation and adoption of sophisticated ICT solutions: Case studies of SMEs in Lagos, Nigeria. Journal of Systems and Information Technology 13(2): 125-143.

Arendt L. 2008. Barriers to ICT adoption in SMEs: How to bridge the digital divide. Journal of Systems and Information Technology 10(2): 93-108.

Arikpo I, Osofisan A, Usoro A. 2009. Bridging the digital divide: The Nigerian journey so far. International Journal of Global Business 2(1): 181-204.

Ashrafi R, Murtaza M. 2008. Use and impact of ICT on SMEs in Oman. Electronic Journal Information Systems Evaluation 11(3): 125-138. 
Awa H, Eze S, Urieto J, Inyang B. 2011. A major determinant of information technology (IT) adoption by SMEs in Nigeria. Journal of Systems and Information Technology 13(2): 144162.

Ayobami O. 2011. Corruption eradication in Nigeria: An appraisal. Available at: www.webpages.uidaho.edu/ mbolin/ ayobami.htm.

Barba-Sanchez B, Martinez R, Jimenez-Zarco A. 2007. Drivers, benefits and challenges of ICT adoption by small and medium sized enterprises (SMEs): A literature review. Problems and Perspectives in Management 5(1): 103-114.

Bhagwat R, Sharma M. 2007. Information system architecture: A framework for a cluster of small and medium sized enterprise (SMEs). Production Planning and Control 18(4): 283296.

Bhaskaran S. 2008. Relationship marketing and e-business: Operations and strategies of small-to-medium scale food enterprises. Rural Industries Research and Development Corporation.

Bryman A, Bell E. 2009. Business Research Methods, 2nd edn.

Oxford University Press: Oxford.

Bryman A, Bell E. 2011. Business Research Methods, 3rd edn.

Oxford University Press: Oxford.

Chaffey D, White GRT. 2010. Business Information Management: Improving performance using information systems, 2nd edn. Pearson Education: Harlow.

Chibelushi C, Costello P. 2009. Challenges facing W. Midlands ICT-oriented SMEs. Journal of Small Business and Enterprise Development 16(2): 210-239.

Christopher M. 2011. Logistics and Supply Chain Management: Creating value-adding networks, 4th edn. Prentice Hall: Edinburgh.

Chuang T, Nakatani K, Zhou D. 2009. An exploratory study of the extent of information technology adoption in SMEs: An application of upper echelon theory. Journal of Enterprise Information Management 22(1/2): 183-196.

Collins J, Worthington W, Reyes P, Romero M. 2010. Knowledge management, supply chain technologies, and firm performance. Management Research Review 33(10): 947960.

Doucek P, Novotny O. 2007. ICT education and requirements for ICT graduates in the Czech Republic. Proceedings of the 2007 Computer Science and IT Education Conference, Mauritius.

Faloye D. 2014. The adoption of e-commerce in small businesses: An empirical evidence from retail sector in Nigeria. Journal of Business and Retail Management Research 8(2): 54-64.

Fasanghari M, Roudsari F, Chaharsooghi K. 2008. Assessing the impact of information technology on supply chain management. World Applied Science Journal 4(1): 87-93.

Fawcett S, Magnan G, McCarter M. 2008 Benefits, barriers and bridges to effective supply chain management. Supply Chain Management: An International Journal 13(1): 35-48. 
Harindranath G, Dyerson R, Barnes D. 2008. ICT adoption and use in UK SMEs: A failure of initiatives? Electronic Journal Information Systems Evaluation 11(2): 91-96.

Harrison A, Van Hoek R. 2011. Logistics Management and Strategy: Competing through the supply chain, 4th edn. Prentice Hall: Edinburgh.

Hong P, Jeong J. 2006. Supply chain management practices of SMEs: From a business growth perspective. Journal of Enter-prise Information Management 19(3): 292-302.

Hsin C, Anastasia P. 2008. Adoption of supply chain management technologies by small and medium enterprises in the manufacturing sector. Available at: is2.lse.ac.uk/asp/aspecis /20080079.pdf.

Ihua UB. 2009. SMEs key failure-factors: A comparison between the United Kingdom and Nigeria. Journal of Social Sciences 18(3): 199-207.

Jones P, Beynon-Davies P, Muir E. 2003. E-business barriers within the SME sector. Journal of Systems and Information Technology 7(1): 1-26.

Jones P, Packham G, Beynon-Davies P, Pickernell D. 2011. False promises: E-business deployment in Wales' SME com-munity. Journal of Systems and Information Technology 13(2): 163-178.

Jones P, Beynon MJ, Pickernell D, Packham G. 2013. Evaluating the impact of different training methods on SME business performance. Environment and Planning C:

Government and Policy 31(1): 56-81.

Jones P, Packham G, Beynon-Davies P, Simmons G, Pickernell D. 2014. An exploration of the attitudes and strategic responses of sole-proprietor micro-enterprises in adopting ICT. International Small Business Journal 32(3): 285-306.

Kapurubandara M, Lawson R. 2006. Barriers to adopting ICT and e-commerce with SMEs in developing countries: An exploratory study in Sri Lanka. Available at: www.esmaeilkhou.com/articles/9-SriLanka-2006.pdf.

Koh L, Demirbag M, Bayraktar E, Tatoglu E, Zaim S. 2007. The impact of supply chain management practices on performance of SMEs. Industrial Management and Data 107(1): 103-124.

Koppi AJ, Naghdy FJF, Sheard J, Edwards S, Wilson D. 2008. The crisis in ICT education: An academic perspective. Annual Conference of the Australasian Society for Computers in Learning in Tertiary Education, pp. 505-508.

Korpelainen E, Kira M. 2010. Employees' choices in learning how to use information and communication technology systems at work: Strategies and approaches. International Journal of Training and Development 14(1): 32-53.

Li X, Chung C, Goldsby T, Holsapple W. 2008 A unified model of supply chain agility: The work-design perspective. International Journal of Logistics Management 19(3): 408-435.

Llorens A, Llinàs-Audet X, Ras A, Chiaramonte L. 2013. The ICT skills gap in Spain: Industry expectations versus university preparation. Computer Applications in Engineering Education 21(2): 256-264. 
MacGregor RC, Vrazalic L. 2006. The effect of small business clusters in prioritising barriers to E-commerce adoption in regional SMEs. Journal of New Business Ideas and Trends 4(1): 24-42.

Matlay H, Addis M. 2003. Adoption of ICT and e-commerce in small businesses: An HElbased consultancy perspective. Journal of Small Business and Enterprise Development 10(3): 321-335.

Miliszewska I. 2008. ICT skills: An essential graduate skill in today's global economy? Proceedings of the Informing Science \& IT Education Conference, Bulgaria.

Modimogale L, Kroeze J. 2011. The role of ICT within small and medium enterprises in Gauteng. Communications of the IBIMA 2011: 1-13.

Mpofu K, Watkins-Mathys L. 2011. Understanding ICT adoption in the small firm sector in Southern Africa. Journal of Systems and Information Technology 13(2): 179-199.

Nath T, Standing C. 2010. Drivers of information technology use in the supply chain. Journal of Systems and Information Technology 12(1): 70-84.

Nguyen T. 2008. Information technology adoption in SMEs: An integrated framework. International Journal of Entrepreneurial Behaviour and Research 15(2): 162-186.

Nkanga E. 2011. Glo 1 submarine cable launched in Ghana. Available at: www.thisdaylive.com/articles/glo-1-submarine -cable-launched-in-ghana/89481/.

Olatokun WM. 2008. Information development, gender and national ICT policy in Africa: Issues, strategies, and policy options. Information Development 24(1): 53-65.

Olise M, Anigbogu T, Edoko T, Okoli M. 2014. Determinants of ICT adoption for improved SME's performance in Anambra State, Nigeria. American International Journal of Contemporary Research 4(7): 163-176.

Olorunshola JB. 2003. Problems and prospects of small and medium-scale industries in Nigeria. Seminar on Small and Medium Industries Equity Investment Scheme, CBN Training Centre, Lagos.

Olusegun F, Gabriel A, Sushil S, Zhang J. 2006. Factors affecting the adoption of Ecommerce: A study in Nigeria. Journal of Applied Science 6(10): 2224-2230.

Oluwatayo I. 2010. Information and communication technologies as drivers of growth experience from selected small-scale business in rural southwest Nigeria. Available at: www.nai. uu.se/ecas-4/panels/141-156/panel-150/Isaac-Oluwatayo-Full-paper.pdf.

Ongori H, Migiro S. 2010. Information and communication technologies adoption in SMEs: Literature review. Journal of Chinese Entrepreneurship 2(1): 93-104.

Onugu B. 2005. Small and medium enterprises (SMEs) in Nigeria: Problems and prospects. Unpublished PhD thesis, St. Clements University.

Oshikoya T, Hussain N. 2007. Information Technology and the Challenge of Economic Development in Africa. Development Information Service Division (DISD): University of Copenhagen, Denmark and International Books. 
Oxford Economics. 2009. Research Study on High-Level Skills Needed in NI ICT Sector. Department for Employment and Learning. Oxford Economics: Oxford.

Panneerselvam R. 2010. Research Methodology. PHI Learning: New Delhi.

Paul G, Opal D, Vanesa T, Karlene B. 2008. An analysis of factors affecting the adoption of ICT by MSMES in rural and urban Jamaica. Available at:

is2.Ise.ac.uk/asp/aspecis/20080109.pdf.

Pickernell D, Jones P, Packham G, Thomas B, White G, Willis I. 2013. E-commerce trading activity and the SME sector: An FSB perspective. Journal of Small Business and Enterprise Development 20(4): 866-888.

Saunders M, Lewis P, Thornill A. 2007. Research Methods for Business Students, 4th edn. Prentice Hall: Essex.

Saunders M, Lewis P, Thornill A. 2009. Research Methods for Business Students, 5th edn. Prentice Hall: Essex.

Scupola A. 2009. SMEs' e-commerce adoption: Perspectives from Denmark and Australia. Journal of Enterprise Information Management 22(1/2): 152-166.

Shiels H, Mclvor R, O'Reilly D. 2003. Understanding the implications of ICT adoption: Insights from SMEs. Logistics Information Management 16(5): 312-326.

Singh R. 2011. Developing the framework for coordination in supply chain for SMEs. Business Process Management Journal 17(4): 619-638.

Smith DJ. 2007. A Culture of Corruption: Everyday Deception and Popular Discontent in Nigeria. Princeton University Press: Princeton, NJ.

Stavrulaki E, Davis E. 2010. Aligning products with supply chain processes and strategy. International Journal of Logistics Management 21(1): 127-151.

Thakkar J, Kanda A, Deshmukh SG. 2009. Supply chain management for SMEs: A research introduction. Management Research News 32(10): 970-993.

Thomas A. 2006. Research Concept for Management Studies. Routledge: New York, NY. 